\title{
Research on Tele-immersion: Collaborative-Learning Environment with Sharing Knowledge-based
}

\author{
Hongbiao $\mathrm{Xu}$ \\ School of Information and Engineering, Wenzhou Medical College \\ Wenzhou 325000, China \\ E-mail: xuhongbiao0018@163.com
}

The research is financed by education research project of Wenzhou Medical College (No. wyj081402) and science and research project of Wenzhou Medical College (No. XNK07084).

\begin{abstract}
This paper presents the collaborative learning environment with sharing knowledge-based in Tele-immersion. It supports learners have natural interaction, perception and better real experience through working over wide networks of immersed virtual environments. For sharing knowledge, the multi-layer virtual room's model is discussed. It provides a formal model for representing students' knowledge and describing the structure of a domain of knowledge. The combination of Tele-immersion and Collaborative-Learning Environment with Sharing Knowledge-based leads to a framework for intelligent tutoring systems which provides individualized learning to a student.
\end{abstract}

Keywords: Tele-immersion, Knowledge sharing, Collaborative learning environment

\section{Introduction}

\subsection{Tele-immersion}

Tele-immersion technology was originally defined by Tom Defanti in 1996 as the title of a workshop the Electronic Visualization Laboratory (EVL), is "the union of networked VR and video in the context of significant computing and data mining"(Leigh, 1997, p.10). To date, research on Tele-immersion has explosive growth most of its system and performance issues and now focus on supporting collaborative interaction and usability. Tele-immersion now deals with the "[creation of persistent virtual environments] enabling multiple, globally situated participants to collaborate over high-speed and high-bandwidth networks that connected to heterogeneous supercomputing resources and large data stores" (Leigh, 1997, p.10).

\subsection{Computer Supported Collaborative Learning}

CSCL (Computer Supported Collaborative Learning) began in the late 1980s of the 20th century, only 10 years of history. And it had not yet been established a relatively complete theoretical system. In 1996, Koschmann provided a basic framework for CSCL, pointed out that CSCL is an emerging technology that education model of CSCL research tends to be a process rather than experimental methods and not results its emphasis on descriptive. Koschmann, in a report to CSCL2002 conference, gave the General Assembly CSCL definition it considers "CSCL core research areas of interest is in the form of common sense practice and the environment in which these activities of the practice", it's a study of the basic meaning of CSCL. Although not excluded under the control of the quantitative research aimed at learning outcomes, but stressed the more important message experience and studies will be carried out to determine the CSCL research base.

\subsection{Knowledge sharing}

Numerous organizations are now focusing on knowledge management, and particularly on the establishment of an appropriate workplace environment for facilitating knowledge sharing (H.F. Lin, 2007, p.643). Knowledge sharing can be viewed as a form of organizational innovation that has the potential to generate new ideas and develop new various opportunities through socialization and learning processes of knowledge workers (J. Darroch, 2002, p.210).

Knowledge sharing can be defined as a social interaction culture, involving the exchange of people knowledge, experiences, and skills through the whole department or organization. Ardichvili (2003, p.64) discussed knowledge sharing as involving both the supply of and the demand for new knowledge. Van den Hooff (2004, p.117) identified a two-dimension knowledge sharing process, which consists of knowledge donating and 
knowledge collecting. Knowledge donating can be defined as the process of individuals communicating their personal intellectual capital to others, while knowledge collecting can be defined as the process of consulting colleagues to encourage them to share their intellectual capital. In order to facilitate learning and knowledge sharing, organizations must provide support, resources, and a clear mandate that encourages peoples to share their knowledge with others. Moreover, knowledge sharing occurs at both the individual and organizational levels. For individual persons, knowledge sharing is talking to colleagues to help them get something done better, more quickly, or more efficiently. For an organization, knowledge sharing is capturing, organizing, reusing, and transferring experience-based knowledge that resides within the organization and making that knowledge available to others (Hsiu-Fen Lin, 2009, p.25).

\subsubsection{Factors influencing knowledge sharing}

Knowledge is embedded in the myriad communities that constitute organizations, as well as in organizational work practices, values, and systems (K.B. DeTienne, 2001, p.1). Promoting knowledge sharing does not simply involve enhancing people knowledge sharing capabilities or installing an electronic document system. Research concerning the factors affecting knowledge sharing has identified a number of different variables. Lin (2007, p.135) identified employee extrinsic (reciprocal benefits) and intrinsic (knowledge self-efficacy and enjoyment in helping others) motivators as determinants of people knowledge sharing attitudes and intentions. Research supports encouraging and stimulating the development of social interaction culture; knowledge sharing should not be perceived as difficult (H.F. Lin, 2006, p.74). When peoples are embedded in a strong social network, they are motivated to share knowledge with colleagues (M. Huysman, 2004, p.81). A survey by Lin and Lee (H.F. Lin, 2004, p.108) also found that attitudes of senior managers towards knowledge sharing behavior positively influenced intentions to encourage knowledge sharing. Furthermore, researchers identified advanced information and communications technology (ICT) applications and network systems as the primary driver of organizational knowledge sharing (S.L. Pan, 2003, p.71). These quite different perspectives regarding motivations of knowledge sharing can roughly be termed 'social' issues such as people motivators and organizational contexts versus 'technical' issues such as ICT applications.

\section{The combination of the Tele-immersion and the collaborative learning environment}

Tele-immersion is defined as the synthesis of collaborative virtual environments (CVEs), audio and video conferencing, and supercomputing resources and massive data stores, all interconnected and running over high-speed national or worldwide networks (Johnson, 1998, p.498). Tele-immersion enables participants in distant locations to collaborate in a shared environment as if they are in the same room (Kyoung, 2000, p.8). Computer supported collaborative learning (CSCL) is regarded as being a powerful pedagogical process to promote learners' creativity. A computer supported environment allows space for bringing different points of view and resources together to create design rooms in which learners' debate and critique, discussion and reflection, and collaborative knowledge construction can lead to new insights, new ideas, and new artifacts (Ada, 2008, p.17).

In this good virtual collaborative learning environment, learners could be able to watch each other, and seek common progress. Everyone in the advance or retreat will be the companion's attention and evaluation. These external evaluations enable to influence the direction of its future efforts. This collaborative learning environment in a positive and progressive psychological atmosphere, it will be able to encourage them to better develop, comprehensively improve the quality of each collaborator.

\section{Nested knowledge space model}

\section{1 structure of hypertexts}

For designing a good collaborative learning environment, Dietrich Albert and Cord Hockemeyer (1997, p.553) introduced the theoretical concepts of knowledge spaces provide a formal model to describe the structure of a domain of knowledge, and a similar formal structure is used to describe the structure of hypertexts. The combination of knowledge space theory and the formal hypertext model leads to a framework for intelligent tutoring systems which provides individualized learning paths to a student. In the following, we present the core of (Dietrich, 1997, p.553).

\subsubsection{Formal concepts of knowledge space theory}

In knowledge space theory, a field of knowledge is specified by a finite set of items, i.e. problems or tasks a student may or may not be able to solve. Each student can be described by his/her knowledge state, i.e. the subset of items which this student masters. However, since there are prerequisite relationships between the items, not all possible subsets of items are knowledge states. The set of all possible knowledge states is called a 
knowledge space. Such a knowledge space contains the empty set $\emptyset$ and the complete item set $\mathrm{Q}$ as elements, and, for any two knowledge states $\mathrm{K}, K^{\prime} \in K$ their union $K \cup K^{\prime}$ is also a member of $\mathrm{K}$.

We have already mentioned that the set of possible knowledge states is restricted by prerequisite relationships between the items. In knowledge space theory, these relationships are formalized by surmise relations, i.e. quasi-orders on a set $\mathrm{Q}$ of items. Such a surmise relation $\subseteq$ may be interpreted as $q \subseteq q^{\prime}$ if and only if from a correct response to problem $q^{\prime}$ we can surmise a correct response to problem q. Instead, we could also say that mastering item $\mathrm{q}$ is a prerequisite for mastering item $q^{\prime}$.

\subsubsection{A mathematical model for the structure of hypertext}

Albert and Hockemeyer (1997, p.553) have suggested a mathematical model for the structure of a hypertext using the terminology of the Dexter hypertext reference model (Frank Halasz, 1994, p.30). Within the Dexter model, a hypertext consists of a set of components and a set of links between these components. A component consists of a base component (unit of information) and some source and destination anchors which are located on the base component. Links are specified by source anchors and destination anchors and the components on which the anchors are located.

We assume the existence of three sets $\mathrm{B}, \mathrm{S}$, and D of base components, source anchors, and destination anchors, respectively. A component $\mathrm{c}=\left(\mathrm{b}, \mathrm{S}_{\mathrm{C}}, \mathrm{D}_{\mathrm{C}}\right) \in\left(\mathrm{B} \times 2^{\mathrm{S}} \times 2^{\mathrm{D}}\right)$ is a triple constituted by a base component $\mathrm{b} \in \mathrm{B}$, a subset $\mathrm{S}_{\mathrm{C}} \subseteq \mathrm{S}$ of source anchors, and a subset $\mathrm{D}_{\mathrm{C}} \subseteq \mathrm{D}$ of destination anchors. A set $\mathrm{L} \subseteq(\mathrm{C} \times \mathrm{S}) \times(\mathrm{C} \times \mathrm{D})$ where each $1=\left((\mathrm{c}, \mathrm{s}),\left(c^{\prime}, \mathrm{d}\right)\right) \in \mathrm{L}$ fulfills the condition $\mathrm{s} \in \mathrm{S}_{\mathrm{C}}$ and $\mathrm{d} \in \mathrm{D} c^{\prime}$ is called a set of links. A pair $\mathrm{H}=(\mathrm{C}, \mathrm{L})$ is called a hypertext. A link $1=\left(\left(c, s_{c}\right),\left(c^{\prime}, d c^{\prime}\right)\right)$ connects a source anchor $\mathrm{s}_{\mathrm{c}}$ located on a component $\mathrm{c}$ with a destination anchor $\mathrm{d}^{\prime} c^{\prime}$ on a component $c^{\prime}$.

Based on this formalization of links, Dietrich Albert and Cord Hockemeyer (1997, p.553) introduce a binary relation - which describes the linkage between components. For a Hypertext $\mathrm{H}=(\mathrm{C}, \mathrm{L})$, to define the link relation $-\subseteq \mathrm{C} \times \mathrm{C}$ on the set $\mathrm{C}$ of components. For any components $\mathrm{c}, \mathrm{c}^{\prime} \boxminus \mathrm{C}$, we obtain $\mathrm{c}-c^{\prime}$ if and only if there exists a link $1=\left((\mathrm{c}, \mathrm{s}),\left(c^{\prime}, \mathrm{d}\right)\right) \in \mathrm{L}$.

\subsection{Sharing knowledge based on nested knowledge space model}

Dietrich Albert and Cord Hockemeyer (1997, p.553) use the concept of prerequisite relationships to combine knowledge space theory and the mathematical hypertext model to build a framework for intelligent hypertext tutoring systems.

However, there are some defects in the mathematical hypertext model as a collaborative learning environment. In the navigation mess of hypertext link, users easily get lost in the hypertext materials and unable to concentrate on issues of concern to learn.

To solve this problem, many scholars have done a lot of research work, and made a variety of navigation methods, such as back track, highlighting links, history list, fish-eye views, bookmarks and guided tours, etc. However, for the collaborative learning environment system, these tools are inadequate in the navigation function. GAO (1999, p.1437) provides a hypertext learning state space model to control the learning process. Its shortcoming mainly in this model is the complete separation of the concepts of the "knowledge state" and "knowledge point". In practice, a knowledge state can be used as a knowledge point in another broader knowledge state. The model has also overlooked a variety of potential relationships among the knowledge states. Gerhard Weber and Marcus Specht (1997, p.289) introduce ELM-ART II, an intelligent interactive textbook to support learning programming in LISP. The system emphasizes the learning order of the learning process of students, but it does not take into account the correlation relation among courses.

Data's mismanagement, separated usage of study tools and hard for awareness processing widely exist in the traditional collaborative learning environment. And students need to go through several working to find the content of their needs.

So, WANG (2004, p.150) provides the nested knowledge space model based on knowledge space theory. This model can be used to organize and manage learning materials to solve the problem of "disoriented".

Based on nested knowledge space model, we can make the configuration of tools according to knowledge domain, provide a discussion board and test questions for each knowledge domain, and students can fast access to a variety of contents they need through the navigation of knowledge domain, and learn from the systematic history record of the previous learning experiences of the knowledge domain, that more conducive to their learning. 


\section{Sharing knowledge based on multi-layer virtual rooms}

\subsection{CoPs}

There has been a growing focus on the role of communities of practice (CoPs) within the knowledge management domain. CoPs have been described as "groups of people informally bound together by shared expertise and passion for a joint enterprise" (Wenger, 2000, p.139). They are different from teams and functional units as they are self-organizing systems whose lifespan is determined by its members, based on the intrinsic value that membership brings. Such communities are not constrained by time and space and therefore can span organizational boundaries (Wenger, 1998, p.2). CoPs have been identified as effective loci for the creation and sharing of knowledge. Such communities are able to retain dynamic and evolving knowledge within a real-time process that adds context to existing static repositories. Members identify and engage each other with a common set of codes and language. The development of a strong network of likeminded individuals who share a common understanding is conducive to the development of an environment typified by high levels of trust, shared behavioral norms, mutual respect and reciprocity (Lesser, 2001, p.831). Such an environment has been identified as being high in social capital, and has been linked directly with the processes of the creation and sharing of knowledge. (Nahapiet, 1998, p.242).

\subsection{Multi-layer virtual rooms}

According to the nested knowledge space model (WANG, 2004, p.150): we have created multi-layer virtual rooms in response to knowledge domains in the knowledge space, i.e. one kind of communities of practice (CoPs) within the knowledge management domain. Each room represents one knowledge domain or knowledge point. And in the room, all of the people, who can be called students or learners, are similarly interested in the same subject. For knowledge sharing is a voluntary behavior, there must be one manager or teacher who organizes and manages the knowledge in this room and has confidence in his own knowledge to share it with learners. The students can directly communicate with the teacher for various problems. For example, they can directly talk to the teacher for their seeking answers, or use behavior language to describe what they want.

Once there are more students for the same problem in case of doubt, the teacher can always lecture to the students timely. Similarly, students can communicate with each other to exchange learning methods, to share experiences, and so on. At the same time, all of the communicating process can be recorded and compiled as topic-related information repositories, and enrich the learning materials. If you have bad luck that when you come in the room, just only one is there, it's you; then, you can only help yourself to find related information on this topic to learn alone in this room.

\subsubsection{Quasi-order}

According to the knowledge quasi-orders, to study new knowledge must meet some preconditions, i.e. to learn new knowledge must have master the prerequisite of the knowledge. Only when passing the related knowledge examination, you can get the key, which is certificate of examination, to enter the next advanced room that has the bigger number. Each key has its rank, and when the rank of the key is equal to or higher than the rank of the room, the student who has this key can enter this room or the less rank rooms.

\subsubsection{Public channel}

Of course, in order to help learners to communicate with each other, not limited to the students in the same room, we can open a public channel for broadcasting. And so the question submitted may possess the online person's attention. It's convenient for the higher rank students provide help for the learners. The higher rank student can enter the less rank room anytime, so he can review the knowledge he has studied, or he can timely fly into the less rank room to help the learner who needs help.

\subsubsection{Public place}

To facilitate communication, not only to provide a public channel loudspeaker, but also you can create a public place, which has no rank or has the least rank, for all people to communicate problems. When the learner comes firstly in this virtual collaborative learning environment, he will be there, the public place. And when the student leaves the room and want to exit from the virtual environment, he will also firstly appear in this public place. So that, more people can meet each other at this public place. More meeting chances are more communicating chances.

\subsubsection{Friend feature}

What is important for knowledge sharing is building and developing a dyadic relationship between knowledge transmitters and knowledge receivers. If these two actors lack mutual trust, it is feasible and likely that their 
contributions will not be acknowledged. So, we can add a function to design the friend feature. So that, when you meet a person in any place, you can add his name to friends list if he agrees with you. After that, each time the friend is online, his name will be highlighted to notify you, which is convenient for you to pay attention to the friend at the first time, and you can contact with him at any time for learning from each other.

\subsubsection{Relations among the virtual rooms}

Now we come to a more detailed description of relationships among the multi-layer virtual rooms. As shown in figure 1.

In figure 1 only show two buildings, each building we assume 4 layers; of course, the real situation is more complicated: there are more buildings, and more rooms. And there is a public place in figure 1. Different building represents different knowledge learning line. Such as B1 building represents the computer knowledge, B2 building represents the medical knowledge; or B1 is on behalf of Discrete Mathematics, B2 is on behalf of the data structure.

Parallel relation: The relationship among different buildings is in parallel relation, so that you can not only choose any of them to learn, but also choose two to learn the contents of the building, or even more. For example, you can choose computer knowledge to learn, or medical knowledge can also be chosen to study, or both are selected.

Quasi-order relation: The relationship between the rooms from the lower to the upper, those rooms are in the same building, is on behalf of the quasi-order relation. For example, if you want to learn the knowledge of the room R2, you must first learn the knowledge of the room R1, and if you want to learn the contents of the room $\mathrm{R} 3$, you must first learn the contents of room R1 and room R2, and so on.

Direct access relation: In the same building, the relationship between the upper room and the lower room is on behalf of the direct access relation. Such as, the students from the room R4 can directly fly into the room R3, or $\mathrm{R} 2$, even R1, and so on.

Same one relation: In figure 2, the relationship between B1R2 (the room R2 in the building B1) and B2R2 (the room R2 in the building B2) is the same one relation. For example, we assume that B1 is on behalf of "discrete mathematics", B2 is the representative of "data structures". In the building B1, the room R1 represents the "set theory" and the room R2 represents the "graph theory". In the building B2, the room R1 represents "tree", the room R2 represents "graph". The knowledge represented by B1R2 and B2R2 is related, so in the virtual environment, only to create one room to represent the relevant knowledge domain. Therefore, whether we learn the graph theory in discrete mathematics, or learn the graph in data structure, we have to enter the same room firstly.

\section{Conclusion}

Tele-immersion, Computer Supported Collaborative Learning and knowledge sharing are all the hot topics. How to organize the knowledge and manage the knowledge to serve the learners that is more and more important. In our study, we present the multi-layer virtual room's model to solve the knowledge sharing. The multi-layer virtual room's model is based on the nested knowledge space model that in accordance with knowledge space model.

\section{References}

A. Ardichvili, V. Page, \& T. Wentling. (2003). Motivation and barriers to participation in virtual knowledgesharing communities of practice. Journal of Knowledge Management, 71, 64-77

Ada W. W. MA. (2008). Computer Supported Collaborative Learning and Social Creativity: A Case Study of Fashion Design. Journal of Information, Information Technology, and Organizations, 3, 17-40

B. Van den Hooff, \& F.D.L. Van Weenen. (2004). Knowledge sharing in context: the influence of organizational commitment, communication climate and CMC use on knowledge sharing. Journal of Knowledge Management, $86,117-130$

Dietrich Albert, \& Cord Hockemeyer. (1997). Adaptive and dynamic hypertext tutoring systems based on knowledge space theory. Artificial Intelligence in Education: Knowledge and Media in Learning Systems, 39, 553-555

Frank Halasz, \& Mayer Schwartz. (1994). The Dexter hypertext reference model. Communications of the ACM, 372, 30-39

GAO Shang, CHANG Gui Ran, \& ZHAO Hong. (1999). A hypertext learning state space model and learning 
control. Journal of computer research \& development, 3612, 1437-1441

Gerhard Weber, \& Marcus Specht. (1997). User Modeling and Adaptive Navigation Support in WWW-Based Tutoring Systems. In: Jameson, A., Paris, C. and Tasso, C. (eds.) User Modeling. Springer-Verlag, Wien, pp. 289-300

H.F. Lin. (2007). A stage model of knowledge management: an empirical investigation of process and effectiveness. Journal of Information Science, 336, 643-659

H.F. Lin. (2007). Effects of extrinsic and intrinsic motivations on employee intentions to share knowledge. Journal of Information Science, 332, 135-149

H.F. Lin, \& G.G. Lee. (2006). Effects of socio-technical factors on organizational intention to encourage knowledge sharing. Management Decision, 441, 74-88

H.F. Lin, \& G.G. Lee. (2004). Perceptions of senior managers toward knowledge-sharing behaviour. Management Decision, 421, 108-125

Hsiu-Fen Lin, Hsuan-Shih Lee, \& Da Wei Wang. (2009). Evaluation of factors influencing knowledge sharing based on a fuzzy AHP approach. Journal of Information Science, 351, 25-44

J. Darroch, \& R. McNaughton. (2002). Examining the link between knowledge management practices and type of innovation. Journal of Intellectual Capital, 33, 210-222

Johnson, A. E., Leigh, J., \& DeFanti T.. (1998). Multi-Disciplinary Experiences with CAVERNsoft Tele-Immersive Applications. Proc. of Fourth International Conference on Virtual System and Multimedia, pp. 498-503

K.B. DeTienne, \& L.A. Jackson. (2001). Knowledge management: understanding theory and developing strategy. Competitiveness Review, 111, 1-11

Kyoung S. Park, Yong J. Cho, Naveen K. Krishnaprasad, Chris Scharver, Michael J. Lewis, Jason Leigh, \& Andrew E. Johnson. (2000). CAVERNsoft G2: A Toolkit for High Performance Tele-Immersive Collaboration, Proc. of the Symposium on Virtual Reality Software and Technology 2000, pp.8-15

Leigh, J., DeFanti, T., Johnson, A., Brown, M., \& Sandin, D.. (1997). Global Tele-immersion: Better Than Being There. Proceedings of ICAT' '97, pp.10-17

Lesser, E.L., \& Storck, J. (2001). Communities of Practice and Organizational Performance. IBM Systems Journal, 404, 831-841

M. Huysman, \& D. de Wit. (2004). Practices of managing knowledge sharing: towards a second wave of knowledge management. Knowledge and Process Management, 112, 81-92

Nahapiet, J, \& Ghoshal, S. (1998). Social Capital, Intellectual Capital and the Organizational Advantage. Academy of Management Review, 232,242-266

S.L. Pan, \& D.E. Leidner. (2003). Bridging communities of practice with information technology in pursuit of global knowledge sharing, Journal of Strategic Information Systems, 121, 71-88

WANG Jinfeng, ZHAN Yongzhao, \& MAO Qirong. (2004). Nested knowledge space model and implementation for the collaborative learning environment. Computer Science, 315, 150-152. (In Chinese)

Wenger, E., \& Snyder, W.M. (2000). Communities of Practice: The organizational frontier. Harvard Business Review, pp. 139-145

Wenger, E. (1998). Communities of Practice: Learning as a Social System. Systems Thinker 9, 5, 2-3 


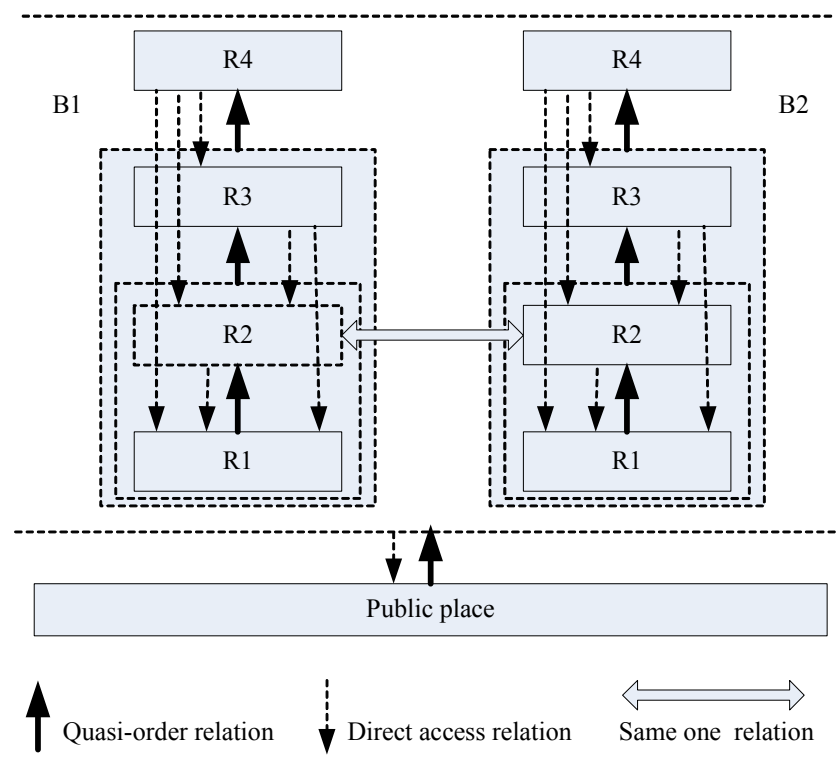

Figure 1. Multi-layer virtual rooms 